\title{
Yüksek Riskli Gebelerde Anksiyete ve Depresyon Düzeyi ile Hemşirelik Bakım Memnuniyetinin İncelenmesi
}

\section{Investigation of Anxiety and Depression Level and Nursing Care Satisfaction in High Risk Pregnant Women}

\author{
Duygu Güleç Şatır ${ }^{1 *}$, Ayşe Eminov², Oya Kavlak ${ }^{3}$ \\ ${ }^{1}$ Ege Üniversitesi Hemşirelik Fakültesi, Kadın Sağlığı ve Hastalıkları Hemşireliği AD, İzmir, Türkiye \\ ${ }^{2}$ Ege Üniversitesi Hastanesi, Kadın Hastalıkları ve Doğum Kliniği, İzmir, Türkiye \\ ${ }^{3}$ Ege Üniversitesi Hemşirelik Fakültesi, Kadın Sağlığı ve Hastalıkları Hemşireliği AD, İzmir, Türkiye \\ e-mail: duygugulec50@hotmail.com,ege.ayseelmin@gmail.com,oya.kavlak@gmail.com \\ orcid: 0000-0002-0226-3985 \\ orcid: $0000-0003-2587-8584$ \\ orcid: 0000-0003-3242-5313 \\ *Sorumlu yazar: Duygu Güleç Şatır
}

Alındı ̆̆ tarih: 30.09.2019

Kabul edildiği tarih: 11.02.2020

DOI: $10.34087 /$ cbusbed626744

$\ddot{\mathbf{O} z}$

Amaç: Yüksek riskli gebelerin anksiyete ve depresyon düzeyi ile hemşirelik bakım memnuniyetinin incelenmesidir. Gereç ve Yöntem: Tanımlayıcı türde olan bu araştırma bir üniversite hastanesinde yüksek riskli gebelik nedeniyle en az 2 gecedir yatan, 108'i 3. trimesterde, 33'ü 2. trimesterde olan toplam 141 gebe üzerinde gerçekleştirilmiştir. Veriler katılımcıların tanıtıcı bilgilerinin yer aldığı anket formu, Hastane Anksiyete Depresyon Ölçeği ve Newcastle Hemşirelik Bakım Memnuniyet Ölçeği ile toplanmıştır.

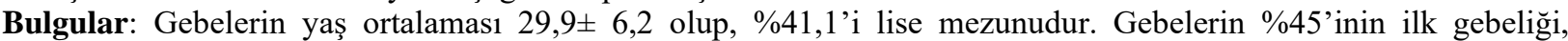
\%60'ının çocuğu bulunmamakta ve \%27'sinin önceki gebeliğinde düşük öyküsü bulunmaktadır. Gebelerin hastanede yattığı gün sayısı ortalaması $4,5 \pm 5,9$ 'dur. Gebelerin anksiyete puan ortalaması $8,0 \pm 4,4$ ve depresyon puan ortalaması $8,4 \pm 4,7$ olarak saptanmıştır. Kesme değerlerine göre gebelerin \% 21,3’ü anksiyete, \%60,3'ü depresyon açısından risk altındadır. Hemşirelik bakım memnuniyeti puan ortalamasının [66,5 $\pm 13,7$ (min:38 - max:100)] orta düzeyde olduğu saptanmıştır. İkinci trimesterdaki gebelerin anksiyete puan ortalaması daha yüksek bulunurken, depresyon düzeyi yüksek olanların bakım memnuniyeti puan ortalaması daha düşük bulunmuştur.

Sonuç: Araştırmada riskli gebelerin depresyon bulguları yüksek, hemşirelik bakımına ilişkin memnuniyetleri ise orta düzeydedir. Depresyon riski yüksek olan gebelerin bakım memnuniyetleri daha düşüktür. Hemşirelerin riskli gebelerde bakım kalitesini ve memnuniyetini arttırabilmek için ruhsal durumlarını ayrıntılı bir şekilde değerlendirmeleri, bu doğrultuda belirlenmiş olan sorunlarla başa çıkma stratejileri geliştirmelerine destek olmaları ve gereksinimleri doğrultusunda profesyonel destek için yönlendirmeleri gerekmektedir.

Anahtar kelimeler: Riskli gebelik, psikoloji, hemşirelik bakımı

\section{Abstract}

Objective: To examine the anxiety and depression levels and satisfaction of nursing care in high-risk pregnant women. Material and Method: This descriptive study was conducted on a total of 141 pregnant women, 108 of them in the third trimester and 33 of the second trimester, who had been hospitalized for at least 2 nights due to high-risk pregnancy in a university hospital. The data were collected with a questionnaire which includes characteristics of participants Hospital Anxiety Depression Scale and Newcastle Nursing Care Satisfaction Scale.

Results: The mean age of the pregnant women was $29.9 \pm 6.2$ and $41.1 \%$ of them were high school graduates. Fortyfive percent of pregnant women have first pregnancy, $60 \%$ have no children and $27 \%$ have a history of miscarriage in their previous pregnancy. The mean number of days of hospitalization of pregnant women was $4.5 \pm-5.9$. The mean score of anxiety subscale was $8.0 \pm 4.4$ and depression was $8.4 \pm 4.7$. According to cut-off scores, $21.3 \%$ of women were at risk for anxiety and $60.3 \%$ were at risk for depression. The mean score of nursing care satisfaction $(66.50 \pm$ 
13.68 (min: 38 - max: 100)) was found to be moderate While the anxiety scores of the pregnant women in the second trimester were found to be higher, the mean score of care satisfaction was lower in those with high depression levels was lower.

Conclusion: In this study, depression symptoms of high-risk pregnant women were high and satisfaction with nursing care was moderate. Satisfaction with care of pregnant women with high risk of depression was lower. In order to increase the satisfaction and quality of care given to risky pregnant women, nurses should evaluate their mental status in detail and support them in developing strategies to cope with the identified problems and direct them for professional support in line with their needs.

Key words: Risk of pregnancy, psychology, nursing care

\section{Giris}

Gebelik heyecanlı ve umutla beklenilen bir süreç olmasına rağmen, fizyolojik değişimler kadar psikolojik değişimlerin de yaşandığı yaşam içerisinde önemli bir geçiş dönemidir [1]. Bu dönemde yaşanan değişimimlerle baş etmeye çalışan gebelerde anksiyete ve depresyon belirtileri, endişe ve streste artma görülebilmektedir [2].

Düşük ekonomik durum, yetersiz sosyal destek, önceki düşük öyküsü gibi bazı faktörler anksiyete ve depresyon prevelansını artırmaktadır [3,4]. Gebelikte anne ve fetüsle ilgili sağlık problemlerinin ortaya çıkması ya da risk yaratan bir komplikasyon gelişmesi ve bu sebeple hastaneye yatma, yaşanan belirsizlik, hastane ortamı, yalnızlık duygusu, iş yaşantısı ve sosyal çevreden ayrı kalma gibi nedenlerle anksiyete ve depresyonun daha da artmasına sebep olmaktadır [5,6]. Yüksek riskli gebelerde anksiyete ve depresyon prevalansı ile ilgili yapıllmış çalışmalar incelendiğinde anksiyete \%12-41 [79], depresyon \%7-47 [7,10-12] oranlarında görülmektedir.

Yüksek riskli gebelik, annenin ve fetüsün sağlığını olumsuz etkileyebilen, bebeğin kaybedilmesi ile sonuçlanabilen, fiziksel, sosyal ve ruhsal değişiklikleri beraberinde getiren bir durumdur. Hastaneye yatışı yapılan ve yatak istirahatine alınan bu gebelerin çeşitli fiziksel ve ruhsal sağlık gereksinimine, sağlık personeli tarafından bilgilendirilmeye ve desteklenmeye ihtiyaçları vardır [1]. Hemşireler gebenin bakım gereksinimlerinin belirlemesinde mesleki bilgi ve beceriyle ve her zaman ulaşılabilir olmalarıyla anahtar rol oynamaktadır. Bu süreçte hemşirelik yaklaşımı gebenin ve yakınlarının sürece uyum sağlamalarını destekleyecek, gereksinimlerini karşılayacak, kaygı ve streslerini azaltacak şekilde planlanmalıdır [5].

Hemşirenin hasta bireye yeterince zaman ayırması, iletişim halinde olması ve gereksinimlerinin karşılaması hasta memnuniyetini de beraberinde getirir. $\mathrm{Bu}$ doğrultuda hastanın bakım algısının ve memnuniyetinin büyük bir kısmını hemşirelik mesleğinin temeli olan hasta hemşire ilişkisi oluşturur [13]. Hemşirelik bakımından memnuniyet duyan hastaların beklenti ve gereksinimlerinin karşılanması ile kendilerini daha önemli hissettiği, tedaviye uyumu kolaylaştığı, yaşam kalitesinde artma gözlendiği belirtilmektedir [14].

Yüksek düzeyde anksiyete ve depresyonun güvensiz anne bebek bağlanmasına ve gebelik komplikasyonlarına sebep olduğu, çocuklarda duygusal, bilişsel ve davranışsal gelişimi olumsuz etkilediği yapılmış çalışmalarda kanıtlanmıştır [15-17]. Bu kapsamda hemşirelerin bakım verirken yüksek riskli gebelerin yaşayabileceği fiziksel ve ruhsal değişimleri iyi gözlemlemeleri ve zamanında müdahalede bulunmaları onların bu süreçten en az düzeyde etkilenmelerini sağlayabilir.

Literatür incelendiğinde yüksek riskli gebelerde duygusal sorunları inceleyen çalışmalar bulunmasına rağmen [7-10] bu gebelerin ruhsal sorunları ile bakım memnuniyetini inceleyen çalışmaya rastlanmamıştır. Bu kapsamda araştırma yüksek riskli gebelerin anksiyete ve depresyon düzeyi ile hemşirelik bakım memnuniyetinin incelenmesi amacıyla yürütülmüştür.

Araştırma soruları şunları içermektedir:

Yüksek riskli gebelik nedeniyle hastanede yatan gebelerde anksiyete ve depresyon ne düzeyde görülmektedir?

Yüksek riskli gebelik nedeniyle hastanede yatan gebelerde anksiyete ve depresyon durumunun hemşirelik bakım memnuniyetiyle ilişkisi var mıdır?

\section{Gereç-Yöntem}

Araştırma yüksek riskli gebelik nedeniyle hastanede yatan gebelerde anksiyete ve depresyon ile hemşirelik bakım memnuniyetinin incelenmesi amacıyla tanımlayıcı olarak gerçekleştirilmiştir. Araştırma Temmuz 2018- Temmuz 2019 tarihleri arasında İzmir'de bir üniversite hastanesinde 2. ve 3. trimesterda olan, yüksek riskli gebelik nedeniyle yatan gebeler üzerinde gerçekleştirilmiştir. Araştırmanın örneklemini evreni bilinmeyen örneklem tekniği [18] ile olayın görülme sıklığı (depresyon ve anksiyete bozuklukları görülme sıklığ 1 \%5-12 [7]) formülü ile gebelerde hesaplanarak en az 73 en fazla 162 gebeye ulaşılması hedeflenmiştir. Araştırmanın örneklemini veri toplama tarihleri arasında en az iki gecedir hastanede yatarak tedavi gören, yüksek riskli gebelik tanısı alan, araştırmaya katılmaya gönüllü, okuma yazma bilen ve Türkçe konuşabilen 108 ' $\mathrm{i}$ üçüncü trimester, 33’ü ikinci trimester olmak üzere 141 gebe oluşturmuştur.

Gebeler preeklemsi, gestasyonel diyabet, çoğul gebelik, intrauterin gelişme geriliği, plasenta previa, Rh uyuşmazlığ 1 , erken doğum tehdidi, erken membran rüptürü, oligohidroamnioz, gebelik kolestazı gibi tıbbi 
tanılara sahiptir. Birçok gebede birden fazla tanı mevcuttur: (örn: gestasyonel diyabet+erken doğum tehdidi veya preeklemsi+erken doğum tehdidi+erken membran rüptürü gibi)

\subsection{Veri Toplama Araçlart}

Araştırma verilerinin toplanmasında riskli gebelerin tanıtıcı bilgilerinin yer aldığ 1 anket formu, Hastane Anksiyete Depresyon Ölçeği (HAD Ölçeği) ve Newcastle Hemşirelik Bakım Memnuniyet Ölçeği (NHMÖ) kullanılmıştır. Anket ve ölçekler hastalara verilerek kendilerinin okuyarak doldurması istenmiştir. Anket formunda gebenin yaşı, eğitim durumu, çalışma durumu, gelir durumu, evlilik yılı gibi demografik bilgiler, obstetrik özellikler (gebelik haftası, gebelik sayısı, düşük, kürtaj sayısı, yaşayan çocuk sayısı, gebeliğin planlı olma durumu) ve kaç gündür hastanede yattığı gibi sorular yer almaktadır.

2.1.1 Hastane Anksiyete Depresyon Ölçeği (HAD Ölçeği) Aydemir ve ark. (1997) [19] tarafından geçerlik ve güvenirliği yapılmış, hastanın anksiyete ve depresyon yönünden riskini belirlemek, düzeyini ve şiddet değişimini ölçmek amacı ile geliştirilmiş bir ölçektir. Ölçekteki tek sayılardan oluşan yedi madde anksiyeteyi ve çift sayılardan oluşan yedi madde depresyonu ölçmektedir Toplam 14 sorudan oluşan ölçek dörtlü likert tipinde olup, 0-3 arasında puanlanmaktadır. Her iki alt ölçekten alınabilecek en düşük puan 0 , en yüksek puan 21 'dir. Aydemir'in ülkemize uyarladığı HAD ölçeğinin kesme noktaları anksiyete alt ölçeği (HAD-A) için 10, depresyon alt ölçeği (HAD-D) için 7 olarak saptanmış, 11 puan ve üzeri anksiyete, 8 puan ve üzeri depresyon açısından riskli grup olarak kabul edilmiştir. Ölçeğin anksiyete alt ölçeği için Cronbach alfa katsayısı 0,85, depresyon alt ölçeği için 0.78 olarak bulunmuştur [19].

$\mathrm{Bu}$ araştırmada ise Cronbach alfa katsayısı anksiyete alt ölçeği için 0,82 depresyon alt ölçeği için 0,78 olarak bulunmuştur.

\subsubsection{Newcastle Hemşirelik Bakım Memnuniyet Ölçeği (NHMÖ)}

Akın ve Erdoğan (2007) [20] tarafından Türk toplumuna uyarlanmış, hemşirelik bakımından memnuniyeti belirlemek amacıyla geliştirilmiş 19 maddeden oluşan, 5'li likert tipinde bir ölçektir. Ölçeğin tüm maddelerinin puanlarının toplamı 100'e dönüştürülerek ölçekten alınan puan hesaplanmaktadır. Toplam puanın 100 olması, hastaların hemşirelik bakımından memnuniyet duyduğunu gösterir. Cronbach alfa katsayısı Akın ve Erdoğan (2007)'ın çalışmasında 0,96 olarak belirlenmiştir [20]. Bu araştırmada ise Cronbach alfa katsayısı 0,97 bulunmuştur.

\section{2.İstatistiksel Analiz}

Araştırma verilerinin istatistiksel analizi için Statistical Package for Social Science for Windows Version 25.0 (SPSS 25.0) bilgisayar programı kullanılmıştır. Araştırmadan elde edilen sosyo-demografik veriler sayı ve yüzde dağılımları ile değerlendirilmiştir. Verilerin normal dağılım gösterip göstermediği KolmogorovSmirnov testi ile test edilmiştir. $\mathrm{P}<0.05$ olduğu için verilerin normal dağılmadığı belirlenmiş ve non parametrik testler kullanılmıştır. Değişkenler arasındaki ilişkiyi incelemek için Non parametrik testlerden Mann Whitney U testi, Kruskall- Wallis testi ve ölçekler arasındaki ilişkilerin incelenmesinde Spearman korelasyon testi kullanılmıştır. Sonuçlar \%95 güven aralığında, anlamlılık $\quad \mathrm{p}<0,05 \quad$ düzeyinde değerlendirilmiştir.

\subsection{Araştırmanın Etik Yönü}

Ölçeklerin kullanılabilmesi için ölçekleri geliştiren yazarlardan izin alınmıştır. Araştırmanın yapılabilmesi için; araştırmanın yapıldığı üniversitenin Tıbbi Araştırmalar Bilimsel Etik Kurulu'ndan onay alınmıştır (21.06.2018/ E.177588) Çalışmanın yürütüldüğü birimden gerekli izinler alınmıştır. (12.09.2018/E.255018). Araştırma kapsamına alınan gebelere görüşme öncesi araştırmanın amacı açıklanmış ve yazılı onamları alınmıştır.

\section{Bulgular}

Araştırmaya alınan yüksek riskli gebelerin yaş ortalaması $29,9 \pm 6,2$ ve $\% 41,1$ 'i lise mezunudur. Gebeler ortalama $31,7 \pm 5,1$ gebelik haftasında olup, \%45,4'ünün ilk gebeliği, \%27'sinin önceki gebeliğinde düşük öyküsü bulunmaktadır (Tablo 1). Diğer tanıtıcı bilgiler Tablo 1 'de yer almaktadir.

Gebelerin tanıtıcı özellikleri ile anksiyete, depresyon alt ölçekleri ve memnuniyet arasındaki ilişki incelendiğinde; yaş, eğitim durumu, çalışma durumu, obstetrik özellikler ve hastanede toplam yatış günü ile anksiyete, depresyon ve memnuniyet puanları arasında anlamlı ilişki saptanmamıştır. İkinci trimester gebelerin anksiyete alt ölçek puan ortalaması $(10,0 \pm 5,0)$ üçüncü trimesterde olan gebelerden $(7,4 \pm 4,0)$ anlamlı oranda yüksek saptanmıştır (Tablo 1).

Gebelerin ölçeklerden aldıkları puanlar incelendiğinde; NHMÖ puan ortalamas1 66,5 $\pm 13,7$ (min: 38, max:100),

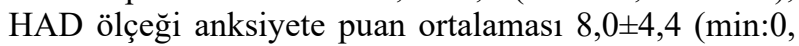
$\max : 21$ ), depresyon puan ortalamas1 $8.41 \pm 4.7$ (min:0, max:21) olarak saptanmıştır. Anksiyete ve depresyon kesme puanlarına göre değerlendirildiğinde gebelerin $\% 21,3$ 'ünün anksiyete, \%60,3'ünün ise depresyon alt ölçek puanı kesme puanının üstünde yer almıştır.

Kesme puanına göre bakım memnuniyeti ilişkisi değerlendirildiğinde; anksiyete alt ölçeği kesme puanına göre bakım memnuniyetinde anlamlı fark saptanmazken $(p=0.784)$, depresyon alt ölçeği kesme puanının altında olanların bakım memnuniyeti puan ortalaması istatistiksel olarak daha yüksek bulunmuştur $(\mathrm{p}=0.012)$ (Tablo 2).

\section{Tartışma}

Yüksek riskli gebelerde anksiyete ve depresyon düzeyi ile hemşirelik bakım memnuniyetinin incelendiği bu çalışmada gebelerin beşte biri (\%20) anksiyete, çoğunluğu (\%60) depresyon açısından risk altında 
Tablo 1. Gebelerin tanıtıcı özellikleri ile anksiyete, depresyon ve memnuniyet puanları arasındaki ilişki

\begin{tabular}{|c|c|c|c|c|c|c|c|c|}
\hline & \multirow[b]{2}{*}{$\mathbf{n}$} & \multirow[b]{2}{*}{$\%$} & \multicolumn{2}{|c|}{ HAD-A } & \multicolumn{2}{|c|}{ HAD-D } & \multicolumn{2}{|c|}{ NHMÖ } \\
\hline & & & $(\mathrm{X} \pm \mathrm{SS})$ & $\begin{array}{c}\text { test } \\
\text { değeri } \\
\text { p değeri }\end{array}$ & $(\mathrm{X} \pm \mathrm{SS})$ & $\begin{array}{c}\text { test değeri } \\
\text { p değeri }\end{array}$ & $(\mathrm{X} \pm \mathrm{SS})$ & $\begin{array}{c}\text { test } \\
\text { değeri } \\
\text { p değeri }\end{array}$ \\
\hline $\begin{array}{l}\text { Eğitim Düzeyi } \\
\text { Okuma yazma } \\
\text { bilen/İlköğretim } \\
\text { mezunu } \\
\text { Lise mezunu } \\
\text { Üniversite mezunu }\end{array}$ & $\begin{array}{l}56 \\
58 \\
27\end{array}$ & $\begin{array}{l}39.7 \\
41.1 \\
19.2\end{array}$ & $\begin{array}{l}8.9 \pm 4.8 \\
7.4 \pm 3.7 \\
7.2 \pm 4.5\end{array}$ & $\begin{array}{c}\mathrm{KW}: 4.528 \\
\mathbf{p}=.104\end{array}$ & $\begin{array}{l}9.4 \pm 5.3 \\
8.1 \pm 4.1 \\
7.1 \pm 4.6\end{array}$ & $\begin{array}{c}\mathrm{KW}: 5.150 \\
\mathbf{p}=.076\end{array}$ & $\begin{array}{l}64.4 \pm 13.7 \\
67.6 \pm 13.2 \\
66.6 \pm 12.5\end{array}$ & $\begin{array}{c}\mathrm{KW}: 1.485 \\
\mathrm{p}=0.476\end{array}$ \\
\hline $\begin{array}{l}\text { Çalışma durumu } \\
\text { Çalışan } \\
\text { Çalışmayan }\end{array}$ & $\begin{array}{l}45 \\
96\end{array}$ & $\begin{array}{l}31.9 \\
68.1\end{array}$ & $\begin{array}{l}7.6 \pm 4.1 \\
8.1 \pm 4.5\end{array}$ & $\begin{array}{l}Z:-.584 \\
\mathbf{p}=.559\end{array}$ & $\begin{array}{l}7.9 \pm 4.6 \\
8.6 \pm 4.8\end{array}$ & $\begin{array}{l}Z:-.663 \\
\mathbf{p}=.507\end{array}$ & $\begin{array}{l}68.9 \pm 13.4 \\
65.4 \pm 13.7\end{array}$ & $\begin{array}{l}Z:-1.603 \\
p=0.109\end{array}$ \\
\hline $\begin{array}{l}\text { Gelir durumu } \\
\text { algısı } \\
\text { Gelir giderden az } \\
\text { Gelir giderden fazla } \\
\text { Gelir gidere denk }\end{array}$ & $\begin{array}{c}16 \\
7 \\
118\end{array}$ & $\begin{array}{c}11.3 \\
5.1 \\
83.7\end{array}$ & $\begin{array}{l}8.3 \pm 5.4 \\
8.4 \pm 4.6 \\
7.9 \pm 4.3\end{array}$ & $\begin{array}{c}\mathrm{KW}: 0.309 \\
\mathbf{p}=0.857\end{array}$ & $\begin{array}{l}8.6 \pm 5.4 \\
8.3 \pm 5.6 \\
8.4 \pm 4.6\end{array}$ & $\begin{array}{c}0.162 \\
\mathbf{p}=.922\end{array}$ & $\begin{array}{l}68.4 \pm 14.5 \\
73.7 \pm 10.5 \\
66.5 \pm 13.7\end{array}$ & $\begin{array}{c}\mathrm{KW}: 3.161 \\
\mathrm{P}=0.206\end{array}$ \\
\hline $\begin{array}{l}\text { Trimester } \\
2 \text { (14-27 hafta) } \\
3 \text { (28-40 hafta) }\end{array}$ & $\begin{array}{c}33 \\
108\end{array}$ & $\begin{array}{l}23.4 \\
76.6\end{array}$ & $\begin{array}{c}10.0 \pm 5.0 \\
7.4 \pm 4.0\end{array}$ & $\begin{array}{c}Z:-2.540 \\
\mathbf{p}=.011\end{array}$ & $\begin{array}{l}9.8 \pm 5.6 \\
8.0 \pm 4.4\end{array}$ & $\begin{array}{c}Z:-1.538 \\
\mathbf{p}=.124\end{array}$ & $\begin{array}{l}69.9 \pm 16.9 \\
65.4 \pm 12.4\end{array}$ & $\begin{array}{l}Z:-1.282 \\
p=0.200\end{array}$ \\
\hline $\begin{array}{l}\text { Gebelik sayısı } \\
\text { İlk } \\
2 \text { ve üzeri }\end{array}$ & $\begin{array}{l}64 \\
77 \\
\end{array}$ & $\begin{array}{l}45.4 \\
54.6 \\
\end{array}$ & $\begin{array}{l}7.8 \pm 4.1 \\
8.1 \pm 4.7\end{array}$ & $\begin{array}{l}Z:-.133 \\
\mathbf{p}=.894\end{array}$ & $\begin{array}{l}8.7 \pm 4.3 \\
8.2 \pm 5.1 \\
\end{array}$ & $\begin{array}{l}Z:-.951 \\
\mathbf{p}=.342\end{array}$ & $\begin{array}{l}65.2 \pm 12.9 \\
67.6 \pm 14.3\end{array}$ & $\begin{array}{c}Z:-.894 \\
p=0.371\end{array}$ \\
\hline $\begin{array}{l}\text { Yaşayan çocuk } \\
\text { Yok } \\
1 \text { ve üzeri }\end{array}$ & $\begin{array}{l}85 \\
56 \\
\end{array}$ & $\begin{array}{l}60.3 \\
39.7 \\
\end{array}$ & $\begin{array}{l}8.0 \pm 4.3 \\
7.9 \pm 4.7 \\
\end{array}$ & $\begin{array}{l}Z:-.351 \\
\mathbf{p}=.726\end{array}$ & $\begin{array}{l}8.5 \pm 4.4 \\
8.4 \pm 5.3\end{array}$ & $\begin{array}{c}Z:-.222 \\
\mathbf{p}=.824\end{array}$ & $\begin{array}{l}66.7 \pm 13.7 \\
66.3 \pm 13.8 \\
\end{array}$ & $\begin{array}{c}Z:-.148 \\
p=0.882\end{array}$ \\
\hline $\begin{array}{l}\text { Düşük Öyküsü } \\
\text { Var } \\
\text { Yok }\end{array}$ & $\begin{array}{c}38 \\
103\end{array}$ & $\begin{array}{l}27.0 \\
73.0\end{array}$ & $\begin{array}{l}8.0 \pm 4.3 \\
8.0 \pm 4.6\end{array}$ & $\begin{array}{l}Z:-.040 \\
\mathbf{p}=.968\end{array}$ & $\begin{array}{l}8.6 \pm 4.6 \\
7.9 \pm 5.0\end{array}$ & $\begin{array}{c}Z:-.750 \\
\mathbf{p}=.453\end{array}$ & $\begin{array}{l}66.8 \pm 13.7 \\
65.7 \pm 13.8\end{array}$ & $\begin{array}{l}Z:-.355 \\
p=0.722\end{array}$ \\
\hline $\begin{array}{l}\text { Gebeliğin planlı } \\
\text { olması } \\
\text { Evet } \\
\text { Hayır }\end{array}$ & $\begin{array}{c}131 \\
10\end{array}$ & $\begin{array}{l}85.9 \\
14.1\end{array}$ & $\begin{array}{l}8.0 \pm 4.5 \\
8.2 \pm 3.9\end{array}$ & $\begin{array}{c}Z:-.040 \\
\mathbf{p}=0.968\end{array}$ & $\begin{array}{l}8.5 \pm 4.7 \\
7.6 \pm 5.6\end{array}$ & $\begin{array}{l}Z:-.741 \\
\mathbf{p}=.459\end{array}$ & $\begin{array}{l}65.9 \pm 13.4 \\
74.4 \pm 16.0\end{array}$ & $\begin{array}{c}\mathrm{Z}:-.13726 \\
\mathrm{p}=0.084\end{array}$ \\
\hline
\end{tabular}

HAD: Hastane Anksiyete Depresyon Ölçeği, KW: Kruskal Wallis, Z:Mann-Whitney U testi Z değer, n: kişi, NHMÖ: Newcastle Hemşirelik Bakım Memnuniyet Ölçeği, SS: standart sapma,

Tablo 2. Gebelerin anksiyete ve depresyon durumu ile NHMÖ düzeyleri

\begin{tabular}{|c|c|c|c|}
\hline & \multicolumn{3}{|c|}{ NHMÖ } \\
\hline & n(\%) & $\mathrm{X} \pm \mathrm{SS}$ & $\begin{array}{c}\text { test } \\
\text { değeri } \\
\text { p değeri }\end{array}$ \\
\hline HAD-A & & & \\
\hline $\begin{array}{l}\text { Kesme puan } 1 \leq 10 \\
\text { puan }\end{array}$ & $111(78.7)$ & & $\begin{array}{l}Z:-.274 \\
\mathrm{p}=0.784\end{array}$ \\
\hline $\begin{array}{l}\text { Kesme puan } 1 \geq 11 \\
\text { puan }\end{array}$ & $30(21.3)$ & $67.7 \pm 15.4$ & \\
\hline HAD-D & & & \\
\hline $\begin{array}{l}\text { Kesme puan } 1 \leq 7 \\
\text { puan }\end{array}$ & $56(39.7)$ & & $\begin{array}{l}Z:-2.519 \\
\mathbf{p}=\mathbf{0 . 0 1 2}\end{array}$ \\
\hline $\begin{array}{l}\text { Kesme puanı } \geq 8 \\
\text { puan }\end{array}$ & $85(60.3)$ & $64.2 \pm 12.6$ & \\
\hline
\end{tabular}

HAD: Hastane Anksiyete Depresyon Ölçeği, n: kişi, NHMÖ: Newcastle Hemşirelik Bakım Memnuniyet Ölçeği, SS: standart sapma, 
bulunmuştur. Kadınların hemşirelik bakım memnuniyetleri ise orta düzeydedir.

Ülkemizdeki çalışmalar incelendiğinde Gümüşdaş ve ark. (2014) Erzurum'da [21] riskli olan gebelerin sağlıklı gebelere göre kaygı ve stres düzeylerinin daha yüksek olduğunu, Keskin ve ark. (2015) [22] İstanbul'da gestasyonel diyabetli gebelerin \%20'sinin depresyon açısından riskli olduğunu, Uğuz ve ark. (2011) [23] Konya' da intrauterin gelişme geriliği olan gebelerde $\% 30$ anksiyete, \%25,5 major depresyon saptamıştır. Çalışmamızda özellikle depresyon prevalansının yüksek olmasının örneklemin çeşitli komplikasyona sahip gebelerden oluşması ve birçok gebede preeklemsi, gestasyonel diyabet, erken doğum tehdidi gibi birçok komplikasyonun bir arada olmasından kaynaklandığ düşünülmektedir.

Yurtdışındaki çalışmalar incelendiğinde Amerika Birleşik Devletleri'nde Brandon ve ark. (2008) Devletleri'nde [10] riskli gebelerde \%44 oranında depresyon, Byatt ve ark. (2014)'nın [11] \%13 anksiyete, \%27 depresyon, Yeni Zelanda' da Barber ve Starkey (2015) [8] \%37-43 oranında anksiyete bulguları, Yunanistan'da Dagklis ve ark. (2016) [24] ise depresyon oranını \%28 olarak saptamışlardır. Ülkelerin gelişmişlik düzeyi ve sosyokültürel yapıları arasındaki farklar ruhsal sorun görülme oranında etkili olabilir.

Araştırmada ikinci trimester döneminde olan gebelerin anksiyete puan ortalamaları $(10,0 \pm 5,0)$ üçüncü trimester döneminde olan gebelerden $(7,4 \pm 4,0)$ daha yüksek saptanmıştır. Sağlıklı gebelerde gebelik haftası ilerledikçe yaklaşan doğum sürecinin etkisi ile kaygı ve depresyon artmaktadir [25]. Ancak Fransa ve Almanya'da riskli gebelerle yapılan çalışmalarda anksiyetenin gebelik ilerledikçe bizim çalışmamıza benzer şekilde azaldığ 1 görülmektedir [26,27]. Gouronti ve ark. (2015) [28], yüksek riskli gebelerde anksiyete ve depresyon semptomlarının gebelik ilerledikçe azaldığını, kadınların stresli duruma kademeli olarak adapte olduğunu ve kaygının azaldığını belirtmiştir. Anksiyete ve depresyon puanlarının riskli gebelerde gebelik ilerledikçe azalmasının nedeni gebelik haftasının artması ile birlikte bebeğin yaşama şansının da artması düşüncesi olabilir.

Araştırmada riskli gebelerin hemşirelik bakımına ilişkin memnuniyetleri orta düzeyde $(66,5 \pm 13,7)$ bulunmuştur. Çalışmamızla benzer olarak Akbaş (2019)'ın [13] Adana'da ve Bulut ve Taşhan'ın (2017) [29] Bolu'da aynı ölçekle yaptıkları çalışmalarda kadın doğum kliniklerindeki hastaların memnuniyet puan ortalamasını benzer düzeyde (sırayla 67,2 $\pm 16,13 ; 66,6 \pm 20,5$ ) bulmuştur. Alp Y1lmaz ve Başer (2017) [30] ise doğum kliniklerinde yatan annelerin bakım memnuniyetini daha düşük 55,7 \pm 12,1, Tuğut ve Gölbaşı (2013) [14] ise sezaryen olan kadınların bakım memnuniyetini daha yüksek (72,52 $\pm 16,63) \quad$ bulmuştur. Bakım memnuniyetinin hastaların yattığ fiziksel ve çevresel durumuna, sağlık bakımı veren profesyonellere bağlı farklılıklar gösterebileceği düşünülmektedir. Doğum yapan kadınların bakıma yönelik beklentileri riskli gebelerden daha farklı olabilir, bu farklılığın bakım algılarını da o yönde etkileyebileceği düşünülmektedir.

Bu araştırmada gebelerde depresyon düzeyi düşük olanların bakım memnuniyetleri yüksek saptanmıştır. Depresif belirtiye sahip olanların hemşirelik bakımından daha az memnun oldukları söylenebilir. $\mathrm{Bu}$ sebeple depresif belirtiye sahip gebe kadınların memnuniyetlerinin daha yüksek algilayabilecekleri bir hemşirelik bakım sürecinin uygulanmasının önemli olduğu düşünülmektedir. Bu doğrultuda hemşirelerin bakım sürecinde ilk olarak gebelerin fizyolojik ve psikolojik ihtiyaçlarını dikkatli değerlendirmeleri, yeterli beslenme ve istirahati sağlamaları ve güvenli çevreyi oluşturmaları önemli olabilir. Bununla birlikte gebeyle iletişimde güvene dayalı, etkili iletişim becerilerini kullanarak, sürece uyum sağlamaları için etkili baş etme yollarını öğreterek, gereksinimleri doğrultusunda hasta merkezli ve bireyselleştirilmiş bakıma yer vermeleri etkili olabilir.

\section{Araştırmanın sınırlılıkları}

Yüksek riskli gebelerin çoğu aynı anda birçok tanıya sahip olduğu için tanılara (gestasyonel diyabet, erken doğum tehdidi, preeklemsi gibi) göre ölçek puanları analiz edilememiştir.

\section{Sonuc}

Araştırmada riskli gebelerde yüksek oranda depresyon görülmüş ve yüksek oranda depresyona sahip gebeler daha düşük hemşirelik bakım memnuniyeti algısına sahip bulunmuştur. Antenatal anksiyete ve depresyon, anne ve yenidoğan sağlığına olumsuz etkileri nedeniyle obstetrik bakımda mutlaka saptanması, değerlendirilmesi gereken kritik öneme sahiptir. Hastaneye yatan riskli gebelerde ruhsal durum değerlendirmesinin geçerlik ve güvenirliği kanıtlanmış ölçeklerle değerlendirilmesi ve tespit edilmesinin, planlanan hemşirelik bakımı içerisinde yer almasının gerekli olduğu düşünülmektedir.

Hemşireler gebelere bakım verirken yüksek kaygı ya da depresif belirtilere sahip gebeleri stresle baş etme becerileri geliştirmelerine destek olabilir, gerekiyorsa psikiyatri desteğine yönlendirebilirler ve daha büyük risklerin ortaya çıkmasını engelleyebilirler. Bununla birlikte yüksek riskli gebelerde anksiyete ve depresyon düzeylerinin azaltılması ve bakım memnuniyetinin artırılmasına yönelik girişimsel çalışmaların artırılması önerilmektedir.

\section{Referanslar:}

1. Oskay, Ü, Yüksek riskli gebelerde hemşirelik bakımı, Perinatoloji Dergisi, 2004, 12(1), 11-16.

2.Heron, J, O’Connor, T.G, Evans, J, Golding, J, Glover V, The course of anxiety and depression through pregnancy and the postpartum in a community sample, Journal of Affective Disorders, 2004, 80(1), 65 73.

3. Aktas, S, Calik, K.Y, Factors affecting depression during pregnancy and the correlation between social support and pregnancy 
depression, Iranian Red Crescent Medical Journal, 2015,17(9), e16640.

4. Karaçam, Z, Ançel, G, Depression, anxiety and influencing factors in pregnancy, a study in a Turkish population, Midwifery, 2009, 25(4), 344-356.

5.Ölçer, Z, Oskay, Ü, Yüksek riskli gebelerin yaşadığı stresörler ve stresle baş etme yöntemleri, Hemşirelikte Ĕgitim ve Araştırma Dergisi, 2015, 12(2), 85-92.

6. King, N, M, Chambers, J, O’Donnell, K, Jayaweera, S.R,Williamson, C, Glover, V.A, Anxiety, depression and saliva cortisol in women with a medical disorder during pregnancy, Archives of Women's Mental Health, 2010;13(4), 339-345.

7. Thiagayson, P, Krishnaswamy, G, Lim, M.L, Sung, S.C, Haley, C.L Fung, D.S.S, Chen, H, Depression and anxiety in Singaporean highrisk pregnancies prevalence and screening, General Hospital Psychiatry, 2013, 35(2), 112-116.

8. Barber, C.C, Starkey, N.J, Predictors of anxiety among pregnant New Zealand women hospitalised for complications and a community comparison group, Midwifery, 2015,31(9), 888-896.

9. Kang, Y.T, Yao, Y, Dou, J, Guo, X, Li, S.Y, Zhao, C.N, Li, B, Prevalence and risk factors of maternal anxiety in late pregnancy in China, International Journal of Environmental Research and Public Health, 2016, 13(5), 468.

10. Brandon, A.R, Trivedi, M.H, Hynan, L.S, Miltenberger, P.D, Labat, D.B, Rifkin, J. B, Stringer, C.A, Prenatal depression in women hospitalized for obstetric risk, The Journal of Clinica Psychiatry, 2008, 69(4), 635-43.

11. Byatt N, Hicks-Courant K, Davidson A, Levesque R, Mick E, Allison J, Moore Simas TA, Depression and anxiety among high-risk obstetric inpatients, General Hospital Psychiatry, 2014, 36(6), 644 649

12. Hermon, N, Wainstock, T, Sheiner, E, Golan, A, Walfisch, A, Impact of maternal depression on perinatal outcomes in hospitalized women-a prospective study, Archives of Women's Mental Health, 2019, 22(1), 85-91

13. Akbas, M, Patient satisfaction on nursing care, the case of gynecology and obstetrics clinics, Acta Bioethica, 2019, 25(1), 127 136

14. Tuğut, N, Gölbaşı, Z, Bir üniversite hastanesi kadın hastalıkları ve doğum servisinde yatan hastaların hemşirelik hizmetlerinden memnuniyet düzeyleri ve etkileyen bazı faktörler, Koç Universitesi Hemşirelikte Eğitim ve Araştırma Dergisi, 2013, 10(2), 38-44.

15. Martins, C, Gaffan, E.A, Effects of early maternal depression on patterns of infant-mother attachment, a meta-analytic investigation Journal of Child Psychology and Psychiatry, 2000, 41(6), 737-46.

16. Loomans, E.M, Van Dijk, A.E, Vrijkotte, T.G, Van Eijsden, M, Stronks, K, Gemke, R.J, Van den Bergh, BR, Psychosocial stress during pregnancy is related to adverse birth outcomes, results from a large multi-ethnic community-based birth cohort, European Journal of Public Health, 2013, 23(3), 485-91.

17. Alder, J, Fink, N, Bitzer, J, Hösli, I, Holzgreve, W, Depression and anxiety during pregnancy, a risk factor for obstetric, fetal and neonatal outcome? A critical review of the literature, Journal of Maternal Fetal Neonatal Medicine, 2007, 20(3), 189-209.

18. Karataş, N, Araştırmada örnekleme. İçinde: Erefe İ (ed) Hemşirelikte araștırma ilke sürec ve yöntemler, 3.bask1, Ankara 2004, ss:135

19. Aydemir, O, Hastane anksiyete ve depresyon ölçeği Türkçe formunun geçerlilik ve güvenilirliği, Türk Psikiyatri Dergisi, 1997, 8(4), 187-280.

20. Akin, S, Erdogan, S, The Turkish version of the Newcastle Satisfaction with Nursing Care Scale used on medical and surgical patients, Journal of Clinical Nursing, 2007, 16(4), 646-653.

21. Gümüşdaş, M, Apay, S, E,Özorhan, E, Riskli olan ve olmayan gebelerin psiko-sosyal sağlıklarının karşılaştırılması, Sağlık Bilimleri ve Meslekleri Dergisi, 2014,1(2), 32-42.

22. Keskin, F.E, Ozyazar, M, Pala, A.S, Elmali, A.D, Yilmaz, B, Uygunoglu, U, Bozluolcay, M, Tuten, A, Bingol, A, Hatipoglu, E, Evaluation of cognitive functions in gestational diabetes mellitus, Experimental and Clinical Endocrinology \& Diabetes, 2015, 123(4), 246-251.

23. Uguz, F, Gezginc, K, Yazici, F, Are major depression and generalized anxiety disorder associated with intrauterine growth restriction in pregnant women? A case-control study, General Hospital Psychiatry, 2011, 33(6),640.e7-e9.

24. Dagklis, T, Papazisis, G, Tsakiridis, I, Chouliara, F, Mamopoulos, A, Rousso, D, Prevalence of antenatal depression and associated factors among pregnant women hospitalized in a high-risk pregnancy unit in Greece, Social Psychiatry and Psychiatric Epidemiology, 2016, 51(7), 1025-1031.

25. Zaman, F, K, Özkan, N, Toprak, D, Gebelikte depresyon ve anksiyete artar mı? Konuralp Tip Dergisi, 2018, 10(1), 20-25.

26. Beauquier-Maccotta, B, Chalouhi, G.E, Picquet, A.L, Carrier, A, Bussières, L, Golse, B, Ville, Y, Impact of monochorionicity and twin to twin transfusion syndrome on prenatal attachment, post traumatic stress disorder, anxiety and depressive symptoms, PloS one, 2016,11(1), 1-17

27. Brisch, K,H, Munz, D, Bemmerer-Mayer, K, Kachele, H,Terinde, R, Kreienberg, R, Ultrasound scanning for diagnosis of foetal abnormality and maternal anxieties in a longitudinal perspective, $\mathrm{J}$, Reprod, Infant Psychol, 2002, 20, 223-235.

28. Gourounti, C, Karpathiotaki, N, Vaslamatzis, G, Psychosocial stress in high risk pregnancy, International Archives of Medicine, 2015 8(95), 1-9.

29. Bulut, H, Taşhan, S.T, Sezaryan olan kadınların hemşirelik bakımından memnuniyet düzeylerinin belirlenmesi, İn̈̈nü Üniversitesi Să̆llk Bilimleri Dergisi, 2017, 6 (1), 1-6.

30. Alp Yılmaz, F, Bașer, M, Normal doğumda öğrenci hemșireler ve klinik hemşireler tarafindan verilen bakımın anne memnuniyetine etkisi, Acıbadem Üniversitesi Sağllk Bilimleri Dergisi, 2017, (1), 24 28

http://edergi.cbu.edu.tr/ojs/index.php/cbusbed isimli yazarın CBU-SBED başlıklı eseri bu Creative Commons Alıntı-Gayriticari4.0 Uluslararası Lisansı ile lisanslanmışıır.

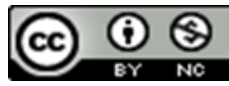

